\title{
Reproductive success of the specialist brood parasite Screaming Cowbird in an alternative host, the Chopi Blackbird
}

\author{
Alejandro G. Di Giacomo ${ }^{1}$ and Juan C. Reboreda ${ }^{2 *}$ \\ 1 Departamento de Conservación, Aves Argentinas/Asociación Ornitológica del Plata, Buenos Aires, Argentina \\ 2 Departamento de Ecología, Genética y Evolución and IEGEBA-CONICET, Facultad de Ciencias Exactas y Naturales, Universidad de \\ Buenos Aires, Buenos Aires, Argentina \\ * Corresponding author: reboreda@ege.fcen.uba.ar
}

Submitted January 20, 2013; Accepted July 4, 2014; Published October 1, 2014

\begin{abstract}
The Screaming Cowbird (Molothrus rufoaxillaris) is the most specialized brood-parasitic cowbird, relying almost entirely on the Bay-winged Cowbird (Agelaioides badius) as host. Recently, Screaming Cowbirds have expanded their range to areas where Bay-winged Cowbirds are absent, and they are exploiting the Chopi Blackbird (Gnorimopsar chopi). Interactions between Screaming Cowbirds and Chopi Blackbirds are largely unexplored, as is the reproductive success of the parasite in this host. Screaming Cowbirds, Chopi Blackbirds, and Bay-winged Cowbirds coexist in northeastern Argentina, providing an ideal system to explore interactions between a specialist brood parasite and an alternative host and to compare the reproductive success of the parasite in its main host and in an alternative host. Screaming Cowbirds parasitized both hosts throughout their breeding seasons (Chopi Blackbirds, mid-October to mid-January; Bay-winged Cowbirds, mid-November to mid-March). Frequency of parasitism was lower in Chopi Blackbirds than in Bay-winged Cowbirds (46\% vs. $74 \%$ ). Nest survival was higher in Chopi Blackbirds than in Bay-winged Cowbirds (37\% vs. $15 \%$ ). In successful nests, survival of Screaming Cowbird eggs and chicks was high and relatively similar in both hosts (Chopi Blackbirds: eggs, 99\%; chicks, 90\%; Bay-winged Cowbirds: eggs, 93\%; chicks, 93\%), but hatchability was lower in Chopi Blackbirds than in Bay-winged Cowbirds (52\% vs. 92\%). Considering (1) nest survival and (2) egg survival, hatchability, and chick survival in successful nests, the reproductive success of Screaming Cowbirds (i.e. proportion of eggs that resulted in fledglings) was 0.17 in Chopi Blackbirds and 0.12 in Bay-winged Cowbirds. Our results indicate that the Chopi Blackbird is a frequent host of the Screaming Cowbird, and parasitism of this alternative host may help explain the range expansion of this parasite in areas of Brazil where the Bay-winged Cowbird is absent.
\end{abstract}

Keywords: brood parasitism, Gnorimopsar chopi, host use, Molothrus rufoaxillaris

\section{Éxito reproductivo del parasito de cría especialista Molothrus rufoaxillaris en un hospedador alternativo, Gnorimopsar chopi}

\section{RESUMEN}

Molothrus rufoaxillaris es el tordo parásito de cría con mayor grado de especialización y depende casi exclusivamente de Agelaioides badius como hospedador. Recientemente $M$. rufoaxillaris ha expandido su rango hacia áreas en las que A. badius está ausente y la evidencia indica que estarían utilizando a Gnorimopsar chopi como hospedador. Las interacciones entre $M$. rufoaxillaris y $G$. chopi son mayormente desconocidas así como el éxito reproductivo del parásito en este hospedador. Las tres especies (M. rufoaxillaris, G. chopi y A. badius) coexisten en el NE de Argentina, ofreciendo un sistema ideal para explorar las interacciones entre un parásito de cría especialista y un hospedador alternativo y para comparar el éxito reproductivo del parásito en sus hospedadores principal y alternativo. $M$. rufoaxillaris parasitó a ambos hospedadores a lo largo de sus temporadas reproductivas (G. chopi: mediados de octubre-mediados de enero; $A$. badius: mediados de noviembre-mediados de marzo). La frecuencia de parasitismo fue menor en G. chopi que en A. badius (46\% vs. $74 \%$ ). La supervivencia de nidos fue mayor en $G$. chopi que en A. badius ( $37 \%$ vs. $15 \%)$. En nidos exitosos, la supervivencia de huevos y pichones fue alta y relativamente similar en ambos hospedadores (G. chopi: 99\% y 90\%; A. badius: $93 \%$ y 93\%), pero el éxito de eclosión fue menor en G. chopi que en $A$. badius (52\% vs. $92 \%$ ). Considerando: 1 ) la supervivencia de nidos, y 2) la supervivencia de huevos, el éxito de eclosión y la supervivencia de pichones en nidos exitosos, el éxito reproductivo de $M$. rufoaxillaris (i.e. proporción de huevos que resultaron en volantones) fue 0.17 en $G$. chopi y 0.12 en $A$. badius. Nuestros resultados muestran que $G$. chopi es un hospedador frecuente de $M$. rufoaxillaris y que el parasitismo de este hospedador alternativo podría ayuda a explicar la expansión del rango de este parásito en áreas de Brasil donde A. badius está ausente.

Palabras clave: parasitismo de cría, Gnorimopsar chopi, uso de hospedadores, Molothrus rufoaxillaris 


\section{INTRODUCTION}

Avian brood parasites, such as cuckoos and cowbirds, lay eggs in nests of other species that provide parental care to their offspring (Ortega 1998, Rothstein and Robinson 1998, Spottiswoode et al. 2012). Some brood parasites are generalists and use a wide variety of hosts, while others are specialists and use one or a few hosts. Specialist parasites are an excellent model for studying coevolutionary processes because, as the interactions occur between two or a few species, it is easier to identify the reciprocal adaptations between hosts and parasites (Rothstein 1990, Krüger 2007).

The Screaming Cowbird (Molothrus rufoaxillaris) is the most specialized cowbird and one of the most specialized avian brood parasites. In most parts of its distribution, it parasitizes only the Bay-winged Cowbird (Agelaioides badius; Hudson 1874, Friedmann 1929, Fraga 1998, De Mársico et al. 2010b). This specialization includes striking similarities: Parasite and host chicks have similar skin and bill coloration (Fraga 1979), and the plumage patterns and begging calls of host and parasite fledglings show a close resemblance (De Mársico et al. 2012). This visual and vocal mimicry is likely the result of a coevolutionary process between the parasite and its main host, because the Baywinged Cowbird does not provide parental care to fledglings whose plumage color and begging calls differ from those of their own young (De Mársico et al. 2012).

Although Screaming Cowbirds appear to be extremely specialized on Bay-winged Cowbirds, reports have indicated that in some parts of their distribution, they also parasitize Chopi Blackbirds (Gnorimopsar chopi; Sick 1985, Fraga 1996). Research suggests that Screaming Cowbird parasitism of Chopi Blackbird nests has evolved recently as the parasite has expanded its range to deforested areas of southeastern Brazil where Bay-winged Cowbirds are absent (Sick 1985, Fraga 2011).

Interactions between Screaming Cowbirds and Chopi Blackbirds are largely unexplored, as is the reproductive success of the parasite in this host. Most available information comes from a study in northeastern Argentina, which reported a high frequency and intensity of Screaming Cowbird parasitism in Chopi Blackbirds (Di Giacomo 2005). In this area, Bay-winged Cowbirds are also present and, as expected, are heavily parasitized by Screaming Cowbirds (Di Giacomo 2005). Interestingly, in this area, frequency distributions of mitochondrial DNA haplotypes differ between Screaming Cowbird chicks from nests of Bay-winged Cowbirds and Chopi Blackbirds (Mahler et al. 2009), which indicates that host use is not random (i.e. some female Screaming Cowbirds specialize in Bay-winged Cowbirds, others in Chopi Blackbirds). Although two previous studies have compared some features of Screaming Cowbird parasitism in Chopi
Blackbirds with those in Bay-winged Cowbirds (De Mársico et al. 2010a, Di Giacomo et al. 2010), neither study analyzed in detail the interactions between Screaming Cowbirds and Chopi Blackbirds.

Here, we analyze a large temporal dataset of Screaming Cowbird parasitism on Chopi Blackbirds in the northeast of Argentina. We report patterns in the frequency and intensity of parasitism, analyze factors that are related to the reproductive success of the parasite in this host, and compare the frequency and intensity of parasitism and the reproductive success of Screaming Cowbirds in Chopi Blackbirds with those in Bay-winged Cowbirds nesting in the same study area.

Considering the relatively high frequency of Screaming Cowbird parasitism in Chopi Blackbirds and the presence of host-specific female lineages, we expected that the parasite's reproductive success in this host would be similar to that in Bay-winged Cowbirds. Estimating the reproductive success of Screaming Cowbirds in Chopi Blackbirds may help us understand the ongoing expansion of Screaming Cowbirds in areas of Brazil where Baywinged Cowbirds are absent. Our results may also help identify host characteristics that allow Screaming Cowbirds to successfully parasitize Chopi Blackbirds, thus contributing to our understanding of host specialization in this parasite.

\section{METHODS}

\section{Study site}

The study was carried out at Estancia "El Bagual" in Formosa Province, Argentina ( $\left.26^{\circ} 18^{\prime} 17.5^{\prime \prime} \mathrm{S}, 58^{\circ} 49^{\prime} 51.1^{\prime \prime} \mathrm{W}\right)$, during the breeding seasons (October-March) from 19961997 to 2007-2008. The area is an open savanna located in the region of the eastern or humid Chaco (Cabrera and Willink 1980). Average annual rainfall at the study site is $1,455 \mathrm{~mm}$ (range: $800-2,200 \mathrm{~mm}$ ), with mean monthly rainfall varying from $40 \mathrm{~mm}$ in midwinter (July) to 215 $\mathrm{mm}$ in early autumn (April). Mean annual temperature is $22.2^{\circ} \mathrm{C}$, and mean monthly temperatures vary from $16.9^{\circ} \mathrm{C}$ in July (with absolute daily minima of $-2^{\circ} \mathrm{C}$ ) to $26.7^{\circ} \mathrm{C}$ in January (with absolute daily maxima of $45^{\circ} \mathrm{C}$ ).

\section{Study Species}

Chopi Blackbirds live in open woodlands, savannas, and palm groves from northern Argentina and Uruguay to Bolivia, southeastern Peru, and northern Brazil (Jaramillo and Burke 1999, Fraga 2011). They mainly nest in preexisting holes, forming colonies of 3-7 nests. Clutch size is 4 or 5 eggs, incubation lasts $14-15$ days, and the chicks remain in the nest for 16-18 days (Di Giacomo 2005). They have helpers at the nest (Fraga 2008).

Bay-winged Cowbirds live in open woodlands and savannas from northern Chubut, Argentina, to eastern 


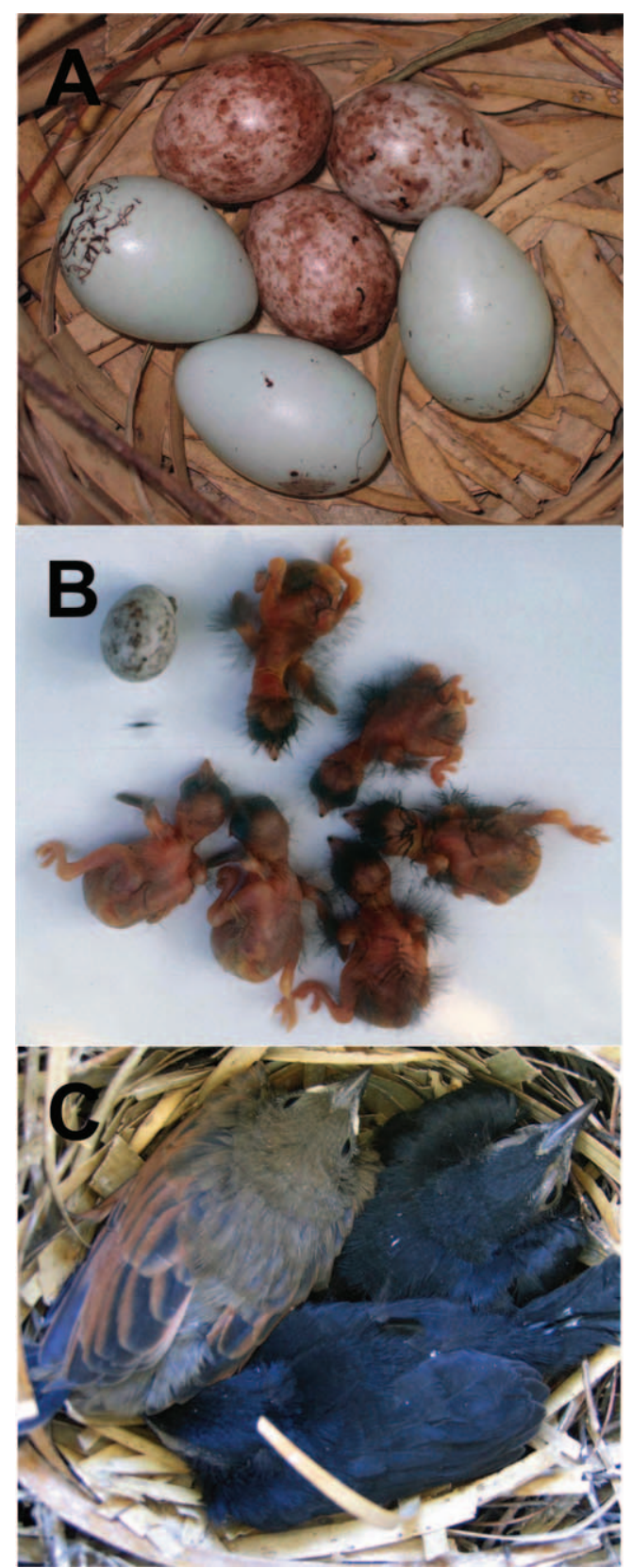

FIGURE 1. Photographs of (A) parasitized clutches of Chopi Blackbirds with 3 host eggs (bottom) and 3 parasite eggs (top). (B) Brood with 1 unhatched parasite egg, 2 parasite chicks (left), and 4 host chicks (right). (C) Brood with 1 parasite chick and 2 host chicks at 10 days of age. Photographs were taken at "El Bagual," Formosa Province, Argentina, by A. G. Di Giacomo.

Bolivia, Paraguay, and central to southeastern Brazil (Jaramillo and Burke 1999, Fraga 2011). They seldom build their nests but exploit a wide variety of covered nesting sites, including old nests built by other species and holes in trees (Fraga 1988, De Mársico et al. 2010b). Clutch size is 3 or 4 eggs, incubation lasts $12-13$ days, and the chicks remain in the nest for 10-13 days (Di Giacomo
2005). They have helpers at the nest (Fraga 1972, Fraga 1991, Ursino et al. 2011).

\section{Data Collection and Analysis}

From 1997 to 2008, we monitored 251 Chopi Blackbird nests; 163 were built in wooden nest boxes, 63 in holes in palm trees, 12 in holes in dry algarrobo (Prosopis alba) trees, 8 in old nests of Firewood-gatherer (Anumbius annumbi), 3 in holes made by Campo Flicker (Colaptes campestris) in wooden light poles, and 2 in the base of palm tree fronds. We placed nest boxes $(30 \mathrm{~cm}$ height, 20 $\mathrm{cm}$ width, $16 \mathrm{~cm}$ depth) in palm trees at a height of 2.5-3.5 $\mathrm{m}$ near natural nests. Nest boxes were separated by $\geq 30 \mathrm{~m}$. Nests were located at 5 colonies that were $1.6-6.6 \mathrm{~km}$ away from each other. We found 121 nests during construction (48.2\%), 51 during host laying (20.3\%), and 79 during incubation (31.5\%).

From 1996 to 2008, we monitored 85 Bay-winged Cowbird nests; 35 were in nests of Little Thornbird (Phacellodomus sibilatrix), 33 in nests of Greater Thornbird (P. ruber), 4 in nests of Lark-like Brushrunner (Coryphistera alaudina), 4 in nests of Golden-winged Cacique (Cacicus chrysopterus), 3 in natural cavities, and the others in nests of Rufous Hornero (Furnarius rufus), Chotoy Spinetail (Schoeniophylax phryganophila), Cattle Tyrant (Machetornis rixosa), Solitary Cacique (C. solitarius), and in a hole made by a Campo Flicker. We found 9 (10.6\%) nests during construction, 34 (40\%) during host laying, 34 (40\%) during incubation, and 8 (9.4\%) after hatching.

We visited Chopi Blackbird and Bay-winged Cowbird nests every 1-3 days until the chicks fledged or the nest failed. We marked individual eggs with waterproof ink and, in a subset of nests selected at random, measured egg length and width with a caliper $( \pm 0.1 \mathrm{~mm})$. During visits, we recorded the numbers of parasite and host eggs. In Baywinged Cowbird nests, we assigned eggs to the host or to Screaming Cowbirds on the basis of background color, spotting pattern, and shape of eggs (Fraga 1983). Chopi Blackbird eggs are easy to differentiate from Bay-winged Cowbird eggs because they differ markedly in size, background color, and spotting pattern (Di Giacomo 2005; Figure 1A). Moreover, we checked for the presence of Shiny Cowbird (Molothrus bonariensis) eggs in both hosts, using eggshell coloration and spotting pattern as diagnostic cues (Fraga 1983).

After hatching, we marked the chicks on the tarsus with waterproof ink and weighed them with $10 \mathrm{~g}$ and $60 \mathrm{~g}$ Pesola scales to the nearest $0.1 \mathrm{~g}$ and $0.5 \mathrm{~g}$, respectively. In Bay-winged Cowbird nests, we assigned nestlings to the host or to Screaming Cowbirds using skin and bill coloration (Fraga 1979). In Chopi Blackbird nests, we discriminated between host and parasite nestlings by differences in skin color and down feathers (Di Giacomo 
TABLE 1. Adult and hatchling body mass and main reproductive parameters of Chopi Blackbirds and Bay-winged Cowbirds at "El Bagual," Formosa Province, Argentina. Values in parentheses are sample size (individuals for body mass; nests for clutch size, egg size, and length of incubation). The column on the right indicates results of statistical comparisons between hosts using MannWhitney U-tests.

\begin{tabular}{lcrr}
\hline & Chopi Blackbird & Bay-winged Cowbird & Comparison \\
\hline Adult body mass (g) & $67.6 \pm 1.6(8)$ & $36.3 \pm 0.6(12)$ & $z=3.7, P<0.001$ \\
Clutch size & $4.4 \pm 0.08(122)$ & $3.3 \pm 0.15(27)$ & $z=5.2, P<0.001$ \\
Egg length (mm) & $26.3 \pm 0.19(24)$ & $23.5 \pm 0.14(47)$ & $z=6.6, P<0.001$ \\
Egg width (mm) & $19.4 \pm 0.08(24)$ & $17.3 \pm 0.08(47)$ & $z=6.9, P<0.001$ \\
Length of incubation (days) & $14.6 \pm 0.1(24)$ & $13 \pm 0(8)$ & $z=4.2, P<0.001$ \\
Body mass at hatching (g) & $4.2 \pm 0.08(20)$ & $3.5 \pm 0.07(14)$ & $z=4.3, P<0.001$ \\
\hline
\end{tabular}

2005; Figure 1B). When nestlings were 8-11 days of age (Figure 1C), we banded them on the tarsus with a numbered aluminum ring and a combination of colored rings.

We estimated host clutch size from nests found during construction and laying that had completed laying. We considered a clutch completed when the number of eggs remained constant for $\geq 2$ consecutive days. To estimate egg size, we first determined the mean egg size for each clutch and then determined the average of the means of all clutches to obtain population values. We estimated the incubation period as the time elapsed from the laying of the last egg to the hatching of the last chick in clutches in which all eggs hatched. We considered a nest parasitized if it received a parasitic egg at any stage of the host's nesting cycle (from prelaying until fledging). We calculated the frequency of parasitism as the number of nests parasitized divided by the number of nests found, and the intensity of parasitism as the number of cowbird eggs laid in parasitized nests.

To quantify Screaming Cowbird reproductive success, we estimated separately (1) nest survival and (2) egg survival and hatchability (in nests that hatched chicks) and chick survival (in nests that fledged chicks). We estimated nest survival rate as the number of successful nests (i.e. nests that fledged chicks) divided by the total number of nests. For this calculation, we considered only nests found during construction or during the host's laying. We estimated egg survival as the number of eggs before hatching divided by the number of eggs laid, hatchability as the number of hatchlings divided by the number of eggs before hatching, and chick survival as the number of fledglings divided by the number of hatchlings. For the calculations of egg survival, we considered only nests found during construction or laying that hatched chicks; whereas for the calculations of hatchability and chick survival, we considered only nests found during construction, laying, or incubation that hatched or fledged chicks, respectively. Finally, we estimated overall reproductive success (i.e. proportion of Screaming Cowbird eggs that resulted in fledglings) as the product of nest survival, egg survival, hatchability, and chick survival.
We captured Chopi Blackbirds and Bay-winged Cowbirds during the breeding season using mist nets and determined their body mass with 60-g and 100-g Pesola scales to the nearest $0.5 \mathrm{~g}$ and $1 \mathrm{~g}$, respectively.

\section{Statistical Analysis}

We used nonparametric statistics because most of our data did not meet the assumptions of parametric tests. We tested differences between hosts in frequency and intensity of parasitism using chi-square tests and Mann-Whitney $U$ tests, respectively. For each host, we tested differences in frequency of parasitism throughout the breeding season and among years using chi-square tests; we tested differences in intensity of parasitism among years using the median test. We tested whether length and width of Screaming Cowbird eggs and weight of Screaming Cowbird chicks differed between hosts using MannWhitney $U$-tests. We used Spearman rank correlations to evaluate the associations between hatchability and clutch size and between chick survival and brood size. We tested differences between hosts in the extent of synchronization between parasitism and the host's laying and nesting success using chi-square tests; we tested differences between hosts in intensity of parasitism, egg survival, hatchability, and chick survival using Mann-Whitney $U$ tests. All tests were two-tailed, and statistical significance was accepted at $P<0.05$. Values presented are means \pm SE.

\section{RESULTS}

\section{Screaming Cowbird Parasitism in Chopi Blackbirds and Bay-winged Cowbirds}

Chopi Blackbirds were larger in adult body mass and had larger eggs, clutch size, and weight at hatching than Baywinged Cowbirds. They also had longer incubation and nestling periods than Bay-winged Cowbirds (Table 1).

Chopi Blackbirds nested from mid-October to early January, most of their nesting attempts (79\%) occurred from early November to mid-December, and Screaming Cowbirds parasitized them during the entire breeding season, but parasitism peaked in November (chi-square 

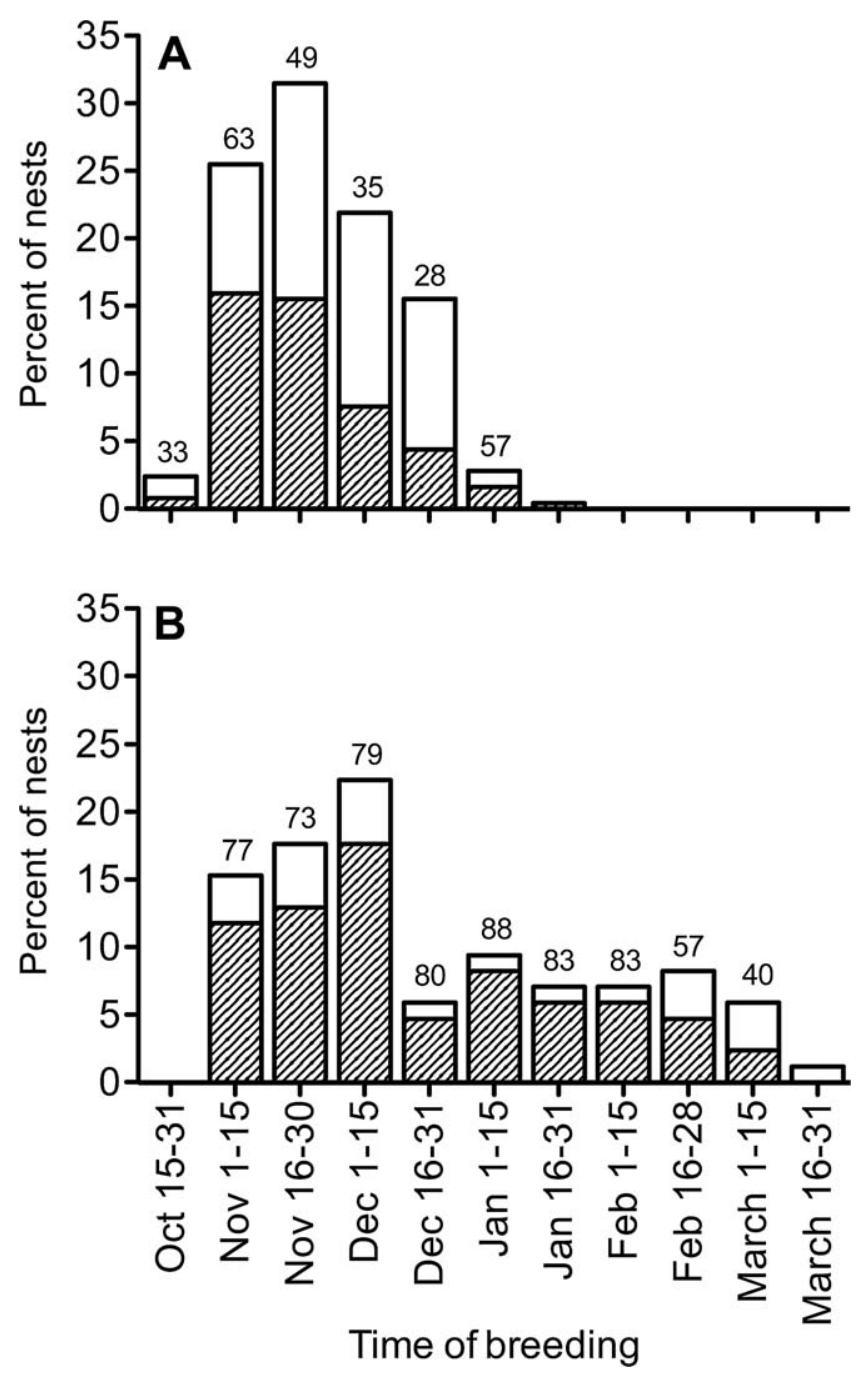

FIGURE 2. Proportion of (A) Chopi Blackbird $(n=251)$ and $(\mathbf{B})$ Bay-winged Cowbird $(n=85)$ nests initiated at different times of the breeding season at "El Bagual," Formosa Province, Argentina. The striped part of the bars indicates the proportion of nests parasitized by Screaming Cowbirds, and numbers above bars indicate the frequency of parasitism at each period. test: $\chi_{5}^{2}=16.0, P=0.007$; Figure 2A). Bay-winged Cowbirds nested from early November to late March, and the majority of nesting attempts (61\%) occurred during November and December (Figure 2B).

Frequency of Screaming Cowbird parasitism was lower in Chopi Blackbirds than in Bay-winged Cowbirds, but intensity of parasitism did not differ between hosts (Table 2). Frequency of parasitism in Chopi Blackbirds was, on average, $46 \%$ and fluctuated among years from $15 \%$ to $70 \%$ (chi-square test: $\chi^{2}{ }_{11}=39.8, P<0.001$; Figure 3A). More than $76 \%$ of parasitized nests were multiply parasitized. Intensity of parasitism was, on average, 3.1 eggs parasitized nest $^{-1}$ (range: $1-12$ eggs, $n=116$ nests) and fluctuated among years from 1.3 to 4.2 eggs (median test: $\chi^{2}=22.0, P$ $=0.02$; Figure 3A).

Frequency of Screaming Cowbird parasitism in Baywinged Cowbirds was, on average, $74 \%$ and fluctuated among years from $29 \%$ to $100 \%$. More than $65 \%$ of parasitized nests were multiply parasitized. Intensity of parasitism was, on average, 2.7 eggs (range: 1-8 eggs) and fluctuated among years from 1.6 to 5.7 eggs (Figure 3B). The small sample sizes for some years precluded statistical analysis.

Synchronization between parasitism and host laying was higher in Chopi Blackbird nests (65\%, $n=341$ events of parasitism) than in Bay-winged Cowbird nests $(49 \%, n=$ 110 events of parasitism) (chi-square test: $\chi^{2}{ }_{1}=8.0, P<$ 0.005). In Chopi Blackbirds, the percentage of parasitic events that occurred during incubation, before host laying, and after hatching were 22,11 , and 7 , respectively, whereas in Bay-winged Cowbirds they were 33, 12, and 6, respectively.

Screaming Cowbird eggs in Chopi Blackbird nests were narrower than those in Bay-winged Cowbird nests (17.7 \pm $0.08 \mathrm{~mm}, n=96$ vs. $17.9 \pm 0.06 \mathrm{~mm}, n=70$; MannWhitney $U$-test: $z=2.3, P=0.02$ ), but they did not differ in length $(22.9 \pm 0.12 \mathrm{~mm}, n=96$ vs. $22.9 \pm 0.11 \mathrm{~mm}, n=$ 70; Mann-Whitney $U$-test: $z=0.12, P=0.90)$. Weight of Screaming Cowbirds at hatching did not differ between Chopi Blackbird and Bay-winged Cowbird nests (3.7 \pm $0.08 \mathrm{~g}, n=11$ vs. $3.4 \pm 0.15 \mathrm{~g}, n=6$; Mann-Whitney $U$ test: $z=1.6, P=0.12)$.

TABLE 2. Frequency and intensity of parasitism and main parameters of Screaming Cowbird reproductive success in nests of Chopi Blackbirds and Bay-winged Cowbirds at "El Bagual," Formosa Province, Argentina. Values in parentheses are sample size (number of nests). The column on the right indicates results of statistical comparisons between hosts (chi-square tests for frequency of parasitism and nesting success, and Mann-Whitney $U$-tests for the other variables).

\begin{tabular}{lccc}
\hline & Chopi Blackbird & Bay-winged Cowbird & Comparison \\
\hline Frequency of parasitism & $46 \%(251)$ & $74 \%(85)$ & $\chi^{2}=18.8, P<0.001$ \\
Intensity of parasitism & $3.1 \pm 0.2(116)$ & $2.7 \pm 0.2(55)$ & $z=1.1, P=0.27$ \\
Nesting success & $37 \%(167)$ & $15 \%(34)$ & $\chi^{2}{ }_{1}=5.4, P=0.02$ \\
Egg survival & $0.99 \pm 0.01(38)$ & $0.93 \pm 0.04(15)$ & $z=1.08, P=0.28$ \\
Hatchability & $0.52 \pm 0.05(63)$ & $0.92 \pm 0.08(8)$ & $z=2.84, P=0.005$ \\
Chick survival & $0.90 \pm 0.04(42)$ & $0.93 \pm 0.07(5)$ & $z=0.10, P=0.92$ \\
\hline
\end{tabular}



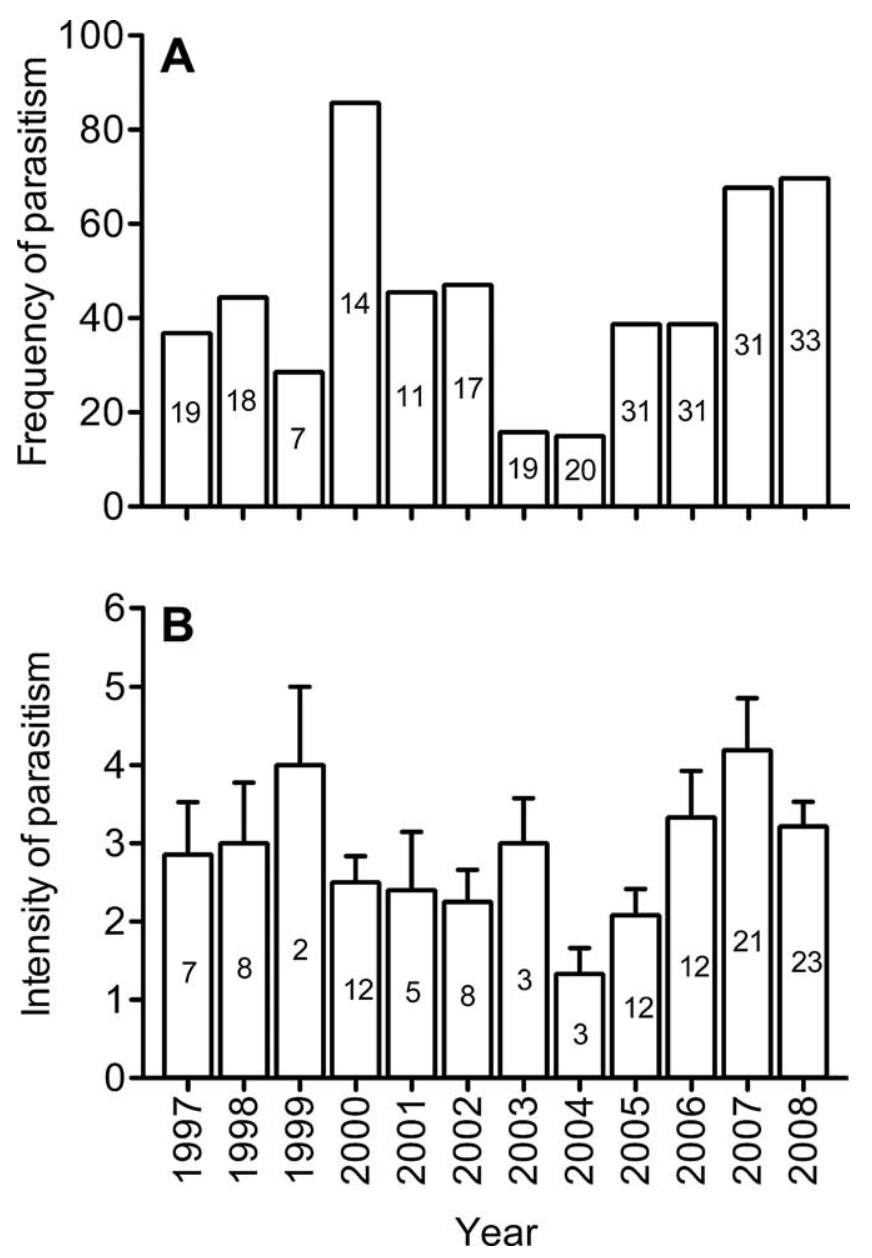

FIGURE 3. Temporal pattern of (A) frequency and (B) intensity of Screaming Cowbird parasitism in Chopi Blackbirds at "El Bagual," Formosa Province, Argentina. The numbers inside the bars indicate $(\mathbf{A})$ total number of Chopi Blackbird nests and (B) number of nests parasitized by Screaming Cowbirds in each year.

We did not record any case of Shiny Cowbird parasitism in Chopi Blackbirds or Bay-winged Cowbirds.

\section{Reproductive Success of Screaming Cowbirds in Chopi Blackbirds and Bay-winged Cowbirds}

Nesting success was higher in Chopi Blackbirds than in Bay-winged Cowbirds (Table 2). In successful nests, hatchability of Screaming Cowbird eggs was lower in Chopi Blackbirds than in Bay-winged Cowbirds, but there were no significant differences between hosts in egg survival and chick survival (Table 2).

The most important factor reducing the reproductive success of Screaming Cowbirds in successful nests of Chopi Blackbirds was hatching failure: Only 52\% of parasite eggs laid during host laying and early incubation hatched. Hatchability of parasite eggs was negatively associated with the total number of eggs in the clutch
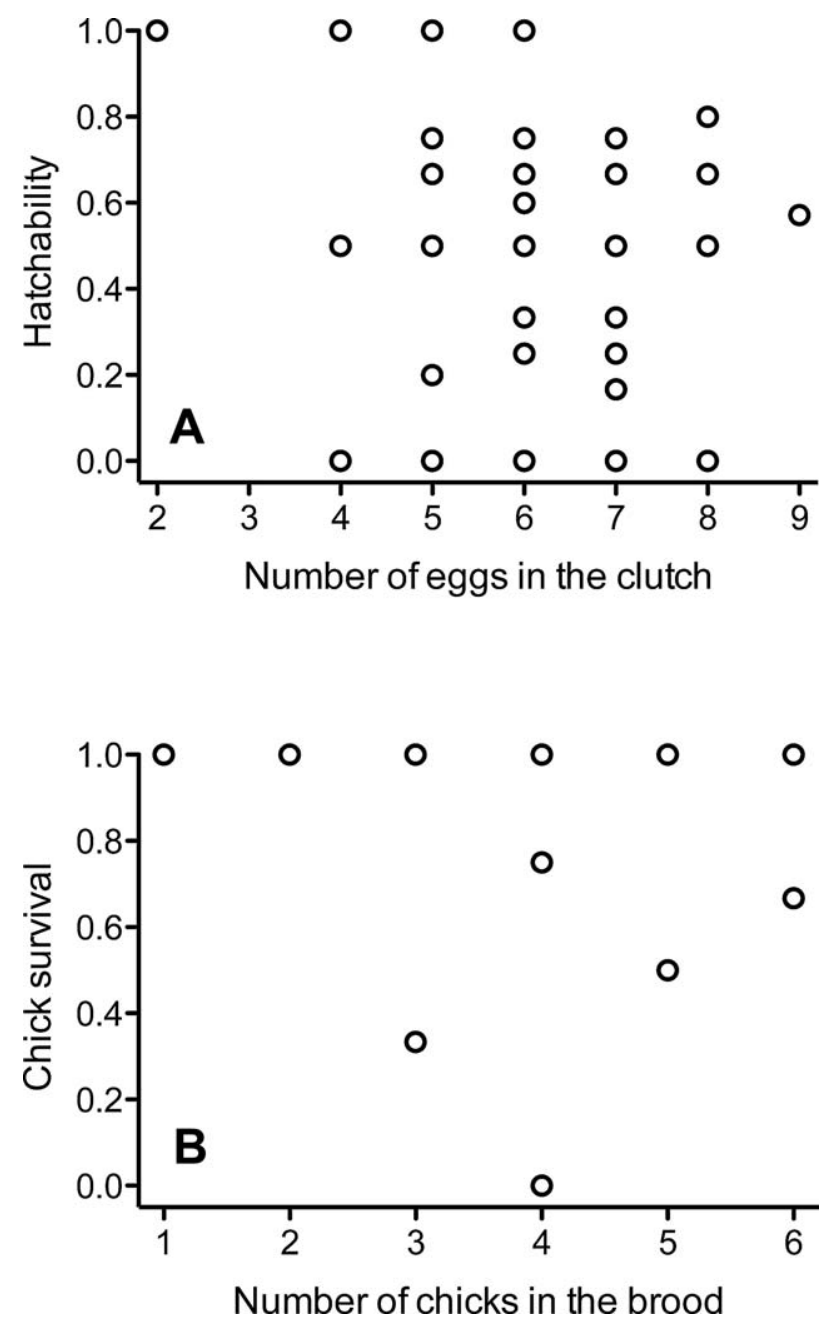

FIGURE 4. Associations between (A) hatchability and total number of eggs (Chopi Blackbird plus Screaming Cowbird) present in the nest during the incubation period $(n=63)$ and (B) chick survival and total number of chicks (Chopi Blackbird plus Screaming (owbird) present in the brood during the nestling period $(n=42)$ at "El Bagual," Formosa Province, Argentina.

(Spearman rank correlation: $r_{\mathrm{s}}=-0.30, P=0.02, n=63$; Figure 4A) but not with the number of host eggs in the clutch (Spearman rank correlation: $r_{\mathrm{s}}=-0.15, P=0.23, n=$ 63 nests).

Survival of parasite chicks throughout the nestling period was, on average, $90 \%$ and was not associated with the number of chicks present in the nest (range: 1-6 chicks, Spearman rank correlation: $r_{\mathrm{s}}=-0.21, P=0.21, n=$ 42 nests; Figure 4B). Regarding losses of parasite eggs during laying and incubation, we observed the puncture of parasite eggs (likely by another parasitic female) in 1 of 38 nests found during prelaying or laying that completed the incubation. We did not observe any case of rejection of parasite eggs laid after Chopi Blackbirds started their own laying ( $n=303$ events of parasitism). We observed 
rejection by ejection or burial only when parasite eggs were laid before those of the host ( $n=38$ events of parasitism).

On average, the number of Screaming Cowbird chicks in Chopi Blackbird nests was $1.82 \pm 0.13$ (range: $1-4$ chicks, $n=49$ nests that hatched parasite chicks), and the number of fledglings was $1.78 \pm 0.13$ (range: $1-4$ chicks, $n=40$ nests that fledged parasite chicks). The reproductive success of Screaming Cowbirds in successful Bay-winged Cowbird nests was as follows: egg survival $=0.93$, hatchability $=0.92$, and chick survival $=0.93$ (Table 2). Considering (1) nest survival and (2) egg survival, hatchability, and chick survival in successful nests, the proportion of Screaming Cowbird eggs that resulted in fledglings was 0.17 in Chopi Blackbird nests and 0.12 in Bay-winged Cowbird nests.

\section{DISCUSSION}

Our results show that Screaming Cowbirds regularly parasitized Chopi Blackbirds in an area where their main hosts, Bay-winged Cowbirds, were also present and that the parasite's reproductive success in this alternative host was as good as that in its main host. We found that the frequency of parasitism was lower in Chopi Blackbirds than in Bay-winged Cowbirds, but the intensity of parasitism did not differ between hosts. Frequency and intensity of parasitism tend to be closely associated, and the explanation for this relationship is that female cowbirds lay eggs at random in nests of their hosts and, therefore, the distribution of eggs in nests approximates a Poisson distribution (Mayfield 1965, Kattan 1997, Lea and Kattan 1998). Further studies are necessary to understand the lack of relationship between frequency and intensity of Screaming Cowbird parasitism in these hosts.

As for the reproductive success of Screaming Cowbirds, the proportion of eggs that resulted in fledglings was 0.17 in Chopi Blackbirds and 0.12 in Bay-winged Cowbirds. Similarly, the overall reproductive success of Screaming Cowbirds in Bay-winged Cowbird nests documented in a study conducted in Buenos Aires Province, Argentina, was 0.14 (De Mársico et al. 2010b). Thus, the reproductive success of Screaming Cowbirds in Chopi Blackbirds appears to be similar in magnitude to that in Bay-winged Cowbirds.

The main factor that reduced Screaming Cowbird reproductive success in successful Chopi Blackbird nests was hatchability. Hatchability was negatively associated with the total number of eggs during incubation but not with the number of host eggs, which indicates that intraspecific competition (multiple parasitism) was the main cause of this decline.

Although the body mass of Screaming Cowbird chicks at hatching was smaller than that of Chopi Blackbirds, parasite chicks were not outcompeted for food by host nest mates, and we observed few cases of brood reduction affecting the parasite chick. One possible explanation for the high survival of Screaming Cowbird chicks in Chopi Blackbird nests is that the parasite's eggs have a shorter incubation period than those of the host (De Mársico et al. 2010b; Table 1) and that most parasitism occurs during host laying. This results in the parasite's chicks hatching before the host's chicks, which gives the former a headstart advantage that increases their chance of successfully competing for food with their larger nest mates. In addition, because this host, like the Bay-winged Cowbird, has helpers at the nest (Fraga 1991, 2008, Ursino et al. 2011), it is likely that rates of food provisioning are high and, therefore, that competition for food between parasite and host chicks is less intense. This situation is similar to that observed in nests of Brown-and-yellow Marshbirds (Pseudoleistes virescens) parasitized by Shiny Cowbirds (Mermoz and Reboreda 2003).

One question that arises from our study is what characteristics of Chopi Blackbirds make them a suitable host for Screaming Cowbirds. When translocated to nests of Chalk-browed Mockingbirds (Mimus saturninus), a species not used as a host by this parasite, Screaming Cowbird chicks are often outcompeted for food by host chicks (De Mársico and Reboreda 2008). By contrast, Screaming Cowbird chicks are rarely outcompeted for food in nests of Brown-and-yellow Marshbirds (Mermoz and Fernández 2003) or Chopi Blackbirds (present study). These 2 alternative hosts, as well as the main host of Screaming Cowbirds, share the particularity of having helpers at the nest, which makes competition for food between parasite and host chicks less intense. These observations suggest that competition for food with host chicks may be a selective force underlying host use in Screaming Cowbirds.

Another shared characteristic of Chopi Blackbirds and Bay-winged Cowbirds is that they are parasitized at low frequencies by Shiny Cowbirds (Sick 1985, Fraga 1998, De Mársico et al. 2010b). At our study site, we did not record any case of Shiny Cowbird parasitism in both hosts, although Shiny Cowbirds are abundant and heavily parasitize Rufous Horneros, Golden-winged Caciques, and Chalk-browed Mockingbirds (Di Giacomo 2005, De Mársico et al. 2010a). This suggests that interspecific competition between parasites may be another selective force underlying host specialization in Screaming Cowbirds. Similar patterns of segregation in host use have been observed in other cowbirds (Chace 2005, Ellison et al. 2006) and cuckoos (Brooker and Brooker 1990) that live in sympatry.

In conclusion, our results indicate that the Chopi Blackbird is a frequent host of the Screaming Cowbird and that its quality is comparable to that of the Bay-winged Cowbird. These results provide empirical support for Sick's 
(1985) suggestion that Screaming Cowbirds expand their range to deforested areas of Brazil using the Chopi Blackbird as host. At present, the northern records of Screaming Cowbirds in Brazil are in the states of Tocantins and Bahia (Fraga 2011), whereas those of Bay-winged Cowbirds are in the south of the state of Mato Grosso do Sul (Jaramillo and Burke 1999), which indicates that Screaming Cowbirds have moved north 1,500-2,000 km using the Chopi Blackbird as host.

\section{ACKNOWLEDGMENTS}

We thank Alparamis SA and Aves Argentinas-Asociación Ornitológica del Plata for allowing us to conduct this study at Estancia "El Bagual." J.C.R. is Research Fellow of CONICET. This study was partially supported by grants from Agencia Nacional de Promoción Científica y Tecnológica and University of Buenos Aires.

\section{LITERATURE CITED}

Brooker, L. C., and M. G. Brooker (1990). Why are cuckoos host specific? Oikos 57:301-309.

Cabrera, A. L., and A. Willink (1980). Biogeografía de América Latina. Serie de Biología 13. Organization of American States, Washington, DC, USA.

Chace, J. F. (2005). Host use by sympatric cowbirds in southeastern Arizona. Wilson Bulletin 117:375-381.

De Mársico, M. C., M. G. Gantchoff, and J. C. Reboreda (2012). Host-parasite coevolution beyond the nestling stage? Mimicry of host fledglings by the specialist Screaming Cowbird. Proceedings of the Royal Society of London, Series B 279:3401-3408.

De Mársico, M. C., B. Mahler, M. Chomnalez, A. G. Di Giacomo, and J. C. Reboreda (2010a). Host use by generalist and specialist brood-parasitic cowbirds at population and individual levels. Advances in the Study of Behavior 42:83-121.

De Mársico, M. C., B. Mahler, and J. C. Reboreda (2010b). Reproductive success and nestling growth of the baywing parasitized by Screaming and Shiny cowbirds. Wilson Journal of Ornithology 122:417-431.

De Mársico, M. C., and J. C. Reboreda (2008). Differential reproductive success favours strong host preference in a highly specialized brood parasite. Proceedings of the Royal Society of London, Series B 275:2499-2506.

Di Giacomo, A. G. (2005). Aves de la Reserva El Bagual. In Historia Natural y Paisaje de la Reserva El Bagual, Provincia de Formosa, Argentina (A. G. Di Giacomo and S. F. Krapovickas, Editors). Temas de Naturaleza y Conservación 4. Aves Argentinas/Asociación Ornitológica del Plata, Buenos Aires, Argentina. pp. 201-465.

Di Giacomo, A. G., B. Mahler, and J. C. Reboreda (2010). Screaming Cowbird parasitism on nests of Solitary Caciques and Cattle Tyrants. Wilson Journal of Ornithology 122:795799.

Ellison, K., S. G. Sealy, and H. L. Gibbs (2006). Genetic elucidation of host use by individual sympatric Bronzed Cowbirds (Molothrus aeneus) and Brown-headed Cowbirds (M. ater). Canadian Journal of Zoology 84:1269-1280.
Fraga, R. M. (1972). Cooperative breeding and a case of successive polyandry in the Bay-winged Cowbird. The Auk 89:447-449.

Fraga, R. M. (1979). Differences between nestlings and fledglings of Screaming and Bay-winged cowbirds. Wilson Bulletin 91: 151-154.

Fraga, R. M. (1983). The eggs of the parasitic Screaming Cowbird (Molothrus rufoaxillaris) and its host, the Bay-winged Cowbird ( $M$. badius): Is there evidence for mimicry? Journal für Ornithologie 124:187-193.

Fraga, R. M. (1988). Nest sites and breeding success of Baywinged Cowbirds (Molothrus badius). Journal für Ornithologie 129:175-183.

Fraga, R. M. (1991). The social system of a communal breeder, the Bay-winged Cowbird Molothrus badius. Ethology 89:195210.

Fraga, R. M. (1996). Further evidence of parasitism of Chopi Blackbirds (Gnorimopsar chopi) by the specialized Screaming Cowbird (Molothrus rufoaxillaris). The Condor 98:866-867.

Fraga, R. M. (1998). Interactions of the parasitic Screaming and Shiny cowbirds (Molothrus rufoaxillaris and M. bonariensis) with a shared host, the Bay-winged Cowbird (Molothrus badius). In Parasitic Birds and Their Hosts: Studies in Coevolution (S. I. Rothstein and S. K. Robinson, Editors). Oxford University Press, New York, NY, USA. pp. 173-193.

Fraga, R. M. (2008). Notes on the nesting of Chopi Blackbirds (Gnorimopsar chopi) in Argentina and Paraguay, with data on cooperative breeding and brood parasitism by Screaming Cowbirds (Molothrus rufoaxillaris). Ornitología Neotropical 19: 299-303.

Fraga, R. M. (2011). Family Icteridae (New World Blackbirds). In Handbook of the Birds of the World, vol. 16: Tanagers to New World Blackbirds (J. del Hoyo, A. Elliott, and D. A. Christie, Editors). Lynx Edicions, Barcelona, Spain. pp. 684-807.

Friedmann, H. (1929). The Cowbirds: A Study in the Biology of Social Parasitism. Charles C. Thomas, Springfield, IL, USA.

Hudson, W. H. (1874). Notes on the procreant instincts of the three species of Molothrus found in Buenos Ayres. Proceedings of the Zoological Society of London 42:153-174.

Jaramillo, A., and P. Burke (1999). New World Blackbirds: The Icterids. A\&C Black, London, UK.

Kattan, G. H. (1997). Shiny Cowbirds follow the 'shotgun' strategy of brood parasitism. Animal Behaviour 53:647-654.

Krüger, O. (2007). Cuckoos, cowbirds and hosts: Adaptations, trade-offs and constraints. Philosophical Transactions of the Royal Society of London, Series B 362:1873-1886.

Lea, S. E. G., and G. H. Kattan (1998). Reanalysis gives further support to the 'shotgun' model of Shiny Cowbird parasitism of House Wren nests. Animal Behaviour 56:1571-1573.

Mahler, B., Y. Sarquis Adamson, A. G. Di Giacomo, V. A. Confalonieri, and J. C. Reboreda (2009). Utilization of a new host in the Screaming Cowbird Molothrus rufoaxillaris, a host specialist brood parasite: Host switch or host acquisition? Behavioral Ecology and Sociobiology 63:1603-1608.

Mayfield, H. (1965). Chance distribution of cowbird eggs. The Condor 67:257-263.

Mermoz, M. E., and G. J. Fernández (2003). Breeding success of a specialist brood parasite, the Screaming Cowbird, parasitizing an alternative host. The Condor 105:63-72.

Mermoz, M. E., and J. C. Reboreda (2003). Reproductive success of Shiny Cowbird (Molothrus bonariensis) parasitizing the 
larger Brown-and-yellow Marshbird (Pseudoleistes virescens) in Argentina. The Auk 120:1128-1139.

Ortega, C. P. (1998). Cowbirds and Other Brood Parasites. University of Arizona Press, Tucson, AZ, USA.

Rothstein, S. I. (1990). A model system for coevolution: Avian brood parasitism. Annual Review of Ecology and Systematics 21:481-508

Rothstein, S. I., and S. K. Robinson (1998). The evolution and ecology of avian brood parasitism: An overview. In Parasitic Birds and Their Hosts: Studies in Coevolution (S. I. Rothstein and S. K. Robinson, Editors). Oxford University Press, New York, NY, USA. pp. 3-56.
Sick, H. (1985). Ornitologia Brasileira: Uma Introducção. University of Brasília, Brasília, Brazil.

Spottiswoode, C. N., R. M. Kilner, and N. B. Davies (2012). Brood parasitism. In The Evolution of Parental Care (N. J. Royle, P. T. Smiseth, and M. Kölliker, Editors). Oxford University Press, Oxford, UK. pp. 226-243.

Ursino, C. A., M. C. De Mársico, M. Sued, A. Farall, and J. C. Reboreda (2011). Brood parasitism disproportionately increases nest provisioning and helper recruitment in a cooperatively breeding bird. Behavioral Ecology and Sociobiology 65:2279-2286. 